\title{
MAGNETIC PULL BY SMES TO ACHIEVE SUSTAINED GROWTH IN THE U.A.E.
}

Tirupathi Anand, SP Jain School of Global Management, U.A.E. Arindam Banerjee, SP Jain School of Global Management, U.A.E. Sadia Riaz, SP Jain School of Global Management, U.A.E.

\section{dx.doi.org/10.18374/RBR-20-2.6}

\begin{abstract}
Small and Medium Enterprises have always been facing the challenge of attracting new customers. There is a churn that happens because of which many customers leave and thus there is a dire need for constantly adding new customers into the business. With intense competition and frequent changes happening in the business environment it is extremely difficult to have a constant flow of new customers in order to sustain and grow the business. The roller-coaster ride of having huge growth in one year followed by a steep fall in the next year can disturb the rhythm of operations for SMEs. It can also demoralize the business owners and managers as these huge fluctuations in the level of business is not easy to handle. Downsizing and upsizing of business in short time may be easy for SMEs but it can severely affect the momentum and thus lead to operational hick-ups and failures. The solution to avoid these huge fluctuations in the level of operations is to have a consistent growth in business with a regular flow of new customers. The author with more than three decades of experience has come up with a formula for attracting new customers for SMEs and this formula is called the "Magnetic Pull". While attracting the new customers the SME owners/managers have to be very careful in ensuring risk management.
\end{abstract}

Keywords: Small and Medium Enterprises; Business Growth; New Customers; Business Performance; Risk Management. 